\title{
DE STEMMING VAN DE BEVOLKING VOÓR, TIJDENS EN NA DE EMANCIPATIE VAN DE SLAVEN IN SURINAME
}

\author{
DOOR
}

\author{
C. F. G. Getrouw
}

In de tijd vóór de Emancipatie - op 1 Juli 1863 — bestond de bevolking van de kolonie uit vrijen en slaven. Tot de vrijen behoorden, als voornaamste hoewel niet grootste groep, de blanken, die de grote landbouw en de handel in handen hadden, of die als gouvernementsambtenaren of militairen een functie bekleedden. Groter was de groep van de vrije Negers en kleurlingen, maar gering hun invloed. Ook de Indianen waren vrij, maar zij namen geen deel aan het leven naar buiten van de kolonie, en aan hun stemming gaven zij op generlei wijze uiting. De Bosnegers waren eveneens vrij; zij waren de nakomelingen van de weggelopen slaven, met wie het Bestuur verdragen gesloten had en voor wie bij een nieuw verdrag in 1856 vele beperkingen in bewegingsvrijheid werden opgeheven (G.B. I856-8). De Marrons waren niet vrij; door Bestuur en overige bevolking werden zij als weglopers en opstandelingen beschouwd; zij waren de onruststokers, met wie men niet op goede voet kon staan.

Van deze bevolkingsgroepen zullen wij in enkele trekken de stemming weergeven in verband met de gebeurtenis van de Emancipatie. De stemmingen hebben zich geuit in verkondigde meningen en in handelingen, die de openbaring waren van hetgeen men dacht en voelde.

Sterker dan ooit was door de Emancipatie in Demerara, in 1834, en in Cayenne, in 1848, het verlangen naar vrijheid in de harten van de Surinaamse slaven opgevlamd. Daarom namen zij de vrijheid, die men hun niet schonk, waar zij maar konden. Uit de districten Coronie en Nickerie, die het dichst bij de Engelse grens liggen, namen velen de vlucht naar Berbice per corjaal

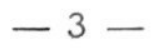


(ZEegelaAR, p. 14-15). Ondanks militaire bewaking wist een slaaf, een zekere Filip, met een schoener van zijn meester er van door te gaan met vele lotgenoten uit Coronie (Id., p. 17-18).

Ongeveer gelijktijdig met deze ontwaakte geest bij de slaven kwam ook een liberale ontwaking, een beter inzicht, bij vele ontwikkelde Nederlanders, hetgeen zich openbaarde zowel bij de Regering als in de Staten-Generaal. Het gevolg hiervan was een stemming van zachtheid, die geleid heeft tot de invoering van een ,,mild slavenreglement" in 1851, dat als nog te streng in 1856 door een milder vervangen werd (G.B. $1856-10)$. Dit reglement beperkte de macht van de eigenaren over hun slaven, het gaf betere voorschriften omtrent huisvesting, voeding, kleding, verpleging en straffen. Een mannelijke slaaf mocht niet meer dan vijftien, een slavin niet meer dan tien zweepslagen krijgen. Ook de contrôle van de landdrosten was een zegen: nu pas begonnen de slaven een gevoel te krijgen, dat men hen voor mensen aanzag. Maar als Gouverneur SchIMpF beweerde, dat in Suriname de slavernij nog maar in naam bestond, was dat zeker niet in overeenstemming met de werkelijkheid. Gelukkig, dat de handhaving van het reglement niet in 's Gouverneurs handen gesteld was, maar in die van de alleszins redelijke en competente Procureur-Generaal Mr J. W. Gefken. Spoedig zagen de slavenmeesters, dat het niet een dode letter was. De P.G. had de werkelijke bedoeling om overtreders er van de voorgeschreven straffen op te leggen. Ook de slaven hadden het recht met hun klachten bij Mr GEFkEN aan te lopen; hij luisterde naar ze en onderzocht alles. En deze gewezen secretaris van de Maatschappij tot afschaffing van de slavernij heeft velen voor het gerecht gebracht. „Het ongelukkig lot gekerkerd te worden is verder het deel geweest van vele planters in de tijd van Proc.-Gen. Gefken" (ZEEgelaAR, p. 27). Wij kunnen ons voorstellen met welk een triomf de slaven zulk een vernedering van een planter vierden! Aan zijn gezag was een zware slag toegebracht; na zijn straf moest hij op een andere plantage te werk gesteld worden. Maar ook hier bleef na korte tijd de reden van zijn verplaatsing aan geen enkele slaaf onbekend.

Zelfs in 1863 werden slaveneigenaren voor het gerecht gebracht wegens het toedienen van meer dan het aantal voorgeschreven zweepslagen. Marianna WolfF werd door het College van Kleine Zaken tot zes dagen gevangenisstraf veroordeeld, omdat zij de slavin LEENTJE, die n.b. niet aan haar toebehoorde, met een stok had geslagen (K.V.I863). Uit de Koloniale Verslagen 
blijkt de strenge toepassing van het Slavenreglement tegenover nalatige directeuren en meesters. $\mathrm{Zij}$ kregen aanschrijving om de slavenwoningen te verbeteren, of om beter voeding te geven, of om het hospitaal te repareren, of om de rusttijden van de slaven in acht te nemen. Werd hieraan geen gevolg gegeven, dan volgde straf. In zijn verslag van het jaar 1862 schrijft de P.G.: ,In het afgelopen jaar had ik mij, met het oog op de toen op handen zijnde emancipatie, tot een strenge handhaving der voorschriften van het reglement der slaven op de plantages en gronden verplicht geacht. Vandaar dan ook de veele [49 stuks!] aanschrijvingen door mij uitgezonden. Ten aanzien van de negerwoningen en ziekenhuizen was ik echter verplicht eenigszins toegevend te zijn, naardien het bezwaarlijk van eigenaren of administrateurs te vergen was zich buitengewoone uitgaven te getroosten, in de onzekerheid waarin velen verkeerden of de plantages na de vrijverklaring der slaven zouden worden aangehouden" (K.V. I862). In hetzelfde verslag zegt $\mathrm{Mr}$ GEFKEN, dat hij toch verplicht was ,,een zeer nalatige bevelhebber eener plantage te bekeuren wegens nalatigheden in onderhoud van de slavenwoningen". Omdat de slaven wisten, wat hun toekwam, traden ze zeer driest op, maar ook dit was geen reden om niet te voorzien in hetgeen voorgeschreven was. Hierover zegt Mr GEFKEN :,,Wat betreft de verstrekking van kleeding-behoeften en wollendekens ben ik met meerdere gestrengheid te werk gegaan en wel hoofdzakelijk met het doel om alle misnoegdheid onder de Negers zooveel moogelijk te voorkomen".

Het ware verkeerd te menen, dat de gunstige stemming van het Gouvernement tegenover de slaven tot gevolg had, dat de rechten van de meesters niet meer werden erkend en beschermd. Niets zou minder waar wezen. Zelfs tot kort voor de Emancipatie kregen de slaven nog hun verdiende straffen, maar nu niet zozeer zweepslagen als wel onthouding van hun bittertje, opsluiting met of zonder boeien, dwangarbeid. In 1861 werd straf opgelegd aan 171 slaven en 87 slavinnen, terwijl op het Piket van Politie aan 174 slaven in totaal 1098 slagen werden toegediend (K.V. I86I). In hetzelfde verslag lezen we, dat de slaaf ADOLF vier dagen opsluiting kreeg zonder boeien, omdat hij de vrije persoon Johanna Clasina BoEck met het woord ,,beest” had uitgescholden. Amba en Josefina kregen resp. zes maanden en één maand gevangenisstraf, omdat zij zich tegenover de politie hadden verzet (K.V. I86I). Het Gouvernement 
beschermde dus de negerslaven, maar liet de meesters niet onbeschermd; het erkende hun rechten. Maar het waren de meesters, voor wie de grens van het recht te eng was; zij waren altijd gewoon geweest met onbegrensde rechteloosheid over hun slaven te heersen, dat zij zich zeer moeilijk konden aanpassen aan de ruimte, die hun nu door de wet toegemeten werd.

Hoe dichter de Emancipatie naderde hoe driester de slaven werden. Het Koloniaal Verslag van I862 spreekt van ,,verregaande ongeregeldheden te Bergendal”, maar ,,gepaste maạtregelen en machtsvertoning herstelden de orde". Ook de cijfers 333 slaven en 136 slavinnen, die gestraft werden, wijzen op erge verstoring van de orde. Op het Piket van Politie werden in 1862 echter slechts aan 42 personen in totaal maar 590 zweepslagen toegediend.

Intussen was in Nederland de wet tot afschaffing van de slavernij aangenomen; het stond vast dat op 1 Juli van het volgende jaar alle slaven hun vrijheid zouden krijgen. Echter was de slechte stemming onder de slaven niet verbeterd door de afkondiging van deze wet bij besluit van 3 October 1862. Opdat alle slaven dit besluit zouden verstaan, had Gouverneur vaN LaNSBERGE het in het Negerengels laten vertalen. In deze proclamatie richtte de Gouverneur zich tot de slaven; hij wenste ze geluk met de aanstaande, spoedige bevrijding en gaf ze een aansporing tot goed gedrag en werkzaamheid. Van de uitwerking van de proclamatie zegt het Kol. Verslag: van 1862 ,De Emancipatiewet werd door de slavenbevolking over het algemeen met kalmte en niet met uitbundige vreugde vernomen". Ook na deze proclamatie bleven slaven nog weglopen. Toen volgde de Algemene Amnestie van 20 October 1862. Als gevolg hiervan keerden vele weglopers terug. In het Verslag staat geschreven: ,,De maatregel der amnestie bleek tenvolle aan de bedoeling te beantwoorden". De hoofdman BRoos echter en zijn bende volhardden in hun wantrouwen tegen het Gouvernement en gaven hun vijandige houding niet op. Pas na de Emancipatie zou hij de tussenkomst van de Evangelische Broeder Gemeente inroepen tot verzoening met het Bestuur. De meeste teruggekeerden kregen geen straf, alleen in 12 gevallen werd rechtsvervolging ingesteld. Maar ook deze goede gezindheid aan de kant van de Overheid was niet bij machte de diep ingewortelde kanker van wantrouwen tegen de blanken uit te roeien. Immers tot nog kort vóór de vrijverklaring, $\mathrm{nl}$. in de eerste helft van 1863, ont- 
brak het bij de slaven niet aan ongehoorzaamheid, verzet en verregaande brutaliteit tegenover de meesters, zoals blijkt uit de getallen van 277 slaven en 93 slavinnen, die in dat half jaar straf van opsluiting en dwangarbeid moesten ondergaan (K.V. I863).

Over de reactie van de slaveneigenaren op de afkondiging van de emancipatiewet lezen we bij ZEEGELAAR (p. 37):,,.... de tijding, die het gelaat van de slaven met een heldere, zichtbare glans verlichtte, tevens dat van vele slaveneigenaren met een sombere, doffe schijn bedekte en laatstbedoelden grote bezorgdheid in plaats van vreugde veroorzaakte". Dat de wet een schadeloosstelling van 300 gld. per slaaf beloofde, was maar een schrale troost. Nog slechter werd de stemming bij deze heren, toen zij zagen met welke grote nauwkeurigheid de verificatie van de slaven plaats vond; de bewijzen dat de slaven hun werkelijk toebehoorden moesten geleverd worden; de slaven moesten aanwezig zijn (G.B. I863-6).

Het slechtst er aan toe waren de eigenaren van plantage Rac à Rac, waar alle slaven op een nacht in 1862 gevlucht waren om zich bij Broos aan te sluiten, nadat zij eerst een groot afscheidsfeest met banja-dans gehouden hadden, waarvan de bedoeling natuurlijk niet begrepen was door directeur en opzichters (ZeEgelaAR, p. $34 ;$ K.V. I862). Het feit van de verificatie bracht echter aan de slaven de overtuiging, dat het ernst was met de vrijverklaring; alle twijfel scheen uitgesloten. ,Op de plantages hoort men sedert de verificatie der slaven niet meer van onlusten" (Z., p. 61).

De Emancipatiedag van 1 Juli 1863 moet een enige dag zijn geweest, een dag, waarvan wij nu ons slechts een flauwe voorstelling kunnen vormen. Hij wordt door de zendeling P. M. LEGÊNE (p. 60) vergeleken met de bevrijdingsdag van Nederland. ,Wie in Nederland 5 Mei 1945 heeft meegemaakt kan de blijdschap beseffen. Hij kan ook begrijpen, dat deze vrijgeworden mensen, zo spoedig dit hun mogelijk was, de plantages verlieten om elders een stuk brood te verdienen, waar zij niet voortdurend werden herinnerd aan die vreselijke tijd van vernedering, ontering en mishandeling".

Het was een Woensdag, een mooie dag met heldere zonneschijn. De Gouverneur had bepaald, dat een algemene dank- en bidstond zou gehouden worden in alle kerken (G.B. I863-18). 
Daarom waren reeds daags te voren de kerken prachtig versierd door de toekomstige vrijen zelf. De godsdienstleraren hadden de mensen voorbereid op een gepaste viering van de vrijheidsdag; zij moesten hun vrijheid aannemen op een christelijke en niet op een heidense manier.

Toen dan ook volgens de voorschriften (G.B. I863-19) de eenen-twintig kanonschoten om zes uur 's morgens aan 33.000 mensen de Emancipatie aankondigden, was het over een land van vrije, opgewekte, dankbare burgers dat de schoten galmden. Maar hoe uitgelaten de feestelingen ook waren, ze gaven op gepaste wijze uiting aan hun vreugde. De militaire patrouilles, welke men uit voorzorg had uitgezonden, hadden niets te doen. Is het niet een grote eer voor onze voorouders, dat alle schrijvers de viering van de Emancipatie als een voorbeeld van orde vermelden? Met voldoening mogen tot vandaag de zendelingen en de missionarissen neerzien op dit bereikte resultaat, dat uitsluitend aan hun arbeid moet worden toegeschreven (THOMSON, p. 141). Mocht het Rapport van de Staatscommissie in 1855 (p. 271) schrijven: ,,Tot dusverre valt er omtrent de uitwerking van het Godsdienstig Onderwijs helaas nog niet veel gunstigs te zeggen", nù openbaarde zich voor allen het tastbare resultaat van dit onderwijs.

Een paar dagen lang heeft men feest gevierd, maar ook hieraan moest een einde komen. Plotseling betrokken de gezichten. Het zou geen tijd worden van zalig niets doen; ook door de vrijen moest er gewerkt worden. Niet weinigen vroegen daarom, of het dan werkelijk vrijheid was, nu zij gedwongen waren een arbeidscontract te sluiten, dat hen verplichtte minstens vier dagen van de week te werken? En dat zij hiermede reeds op 6 Juli moesten beginnen. Op de eerste dag van October moest ieder aan het werk zijn (G.B. I863-20). Het sluiten van de werkcontracten veroorzaakte veel moeilijkheden. Men zag de mensen heen en weer trekken van de ene plantage naar de andere, omdat hier hun dit niet beviel en daar weer iets anders hun tegenstond. Met het geld dat zij ontvangen hadden, waren ze niet zuinig; ze kochten veel in de winkels van de Portugese en Chinese immigranten, die intussen in de handel waren gegaan en kleine winkels hadden opgericht (ZEEGELAAR, p. 66).

De spreekwoordelijke luiheid van de Neger is overdreven. In die dagen hebben velen weliswaar getoond afschuw te hebben van de plantage-arbeid, maar dit was niet in de eerste plaats 
uit luiheid, doch uit een diep gewortelde haat tegen de plantage, met al haar herinneringen aan mishandeling, vernedering en onvrijheid.

Echter boden de getroffen Bestuurs-maatregelen niet veel kans voor een leven van niets doen. Immers, op 16 Juni 1863 was een besluit uitgevaardigd tegen landloperij en bedelarij (G.B. I863-16); en kort daarop werden ook lediggang en zwerverij verboden (Id. -17). Dat deze besluiten niet tot gevolg hadden, dat de verboden euvelen als bij toverslag verdwenen, is alleszins te begrijpen; maar zij die zich er aan schuldig maakten, werden gestraft, hetgeen op anderen een goede uitwerking had.

Zeer wijs moeten wij de handelwijze van het Bestuur noemen, om zich niet alleen van deze negatieve middelen te bedienen, maar ook positief te werk te gaan, o.a. door aan contractanten die goed hadden opgepast, ontheffing van het Staatstoezicht te verlenen. Toch tekent Gouverneur vaN IDSINGA hierbij aan, dat hij van dit recht slechts zeer spaarzaam gebruik maakt, omdat de ontslagenen de mening zijn toegedaan, dat zij ook van elke geregelde arbeid worden vrijgesteld (K.V.I868).

Dat het voor de beheerders van plantages zeer moeilijk was zich in de nieuwe situatie te schikken, daarover behoeven wij ons niet te verbazen.

Nog lang na de Emancipatie vinden we uitlatingen van grote ontstemming bij de vroegere slavenmeesters. Zo bv. in het dagblad $D e$ Kolonist van 1867 . Het nummer van I3 Juni bevat de volgende ontboezeming: „Suriname is niet alleen in kwijnende staat, maar door de onvoorbereide vrijverklaring is het een geheel uit elkaar gerukte maatschappij geworden, welke alleen door veel kennis en voorzichtigheid, echter gepaard met flinke handelingen, weder hersteld kan worden". Mocht in dit nummer de vrijverklaring een onvoorbereide daad genoemd worden, dat van I6 Juni noemt de Emancipatiewet ,,een prachtig kunstgewrocht". De schrijver van dit ingezonden artikel klaagt, dat de geëmancipeerden meer rechten hebben dan de vrijgeborenen. Hij brengt verschillende grieven tegen de gecontracteerden naar voren en spreekt de overtuiging uit, dat alleen openbaring van grieven ,,de eenige anker van hoop is", dat er verbetering komt.

Nog scherper drukte de schrijver van een ingezonden artikel zich uit op 23 Juni, naar aanleiding van de gevallen, dat vrijverklaarden geweigerd hadden "contracten voor het volgende jaar te tekenen, als niet voldaan werd aan hun eis om bepaalde gezagvoerders te verwijderen. Na onderzoek werd aan deze eis voldaan (hetgeen voor ons een bewijs is, dat hij niet ongegrond was!). Maar de verstoorde stemming van de inzender lucht zich aldus: ,,Over enige jaren zullen de nieuwe gezagvoerders aan hetzelfde lot bloot staan naar de wil van de Dames 
en Heren. De Philantropen hebben voldaan aan de zin van hun zwarte Broeders en Zusters. Waar zal deze toegevendheid en valse philantropie toe leiden?".

Toch was de slechte stemming van de gezagvoerders te begrijpen en te verklaren. $\mathrm{Zij}$ hadden te kampen niet alleen met hun veranderde, beperkte positie, maar ook met geldgebrek; ze waren overgeleverd aan de kooplieden, die voorschotten gaven op de plantageproducten, maar die de meeste voordelen naar zich toetrokken. Gebrek aan wissels voor betalingen in het buitenland maakte de kooplieden op hun beurt kregel; het betalen met muntspeciën had bijna alle geld uit het land doen wegvloeien (K.V. I865). Een lichtstraal van hoop gaf de in 1865 opgerichte Surinaamsche Bank, welke geld voorschoot tegen 8, 9, 10, zelfs 11 procent (K.V. I865-'7o). Een tweede lichtstraal kwam van de Nederlandsche Handelmaatschappij, die in 1867 als plantagebezitster optrad. Maar nadat in korte tijd zeven ton van de Surinaamsche Bank over de plantages weggevloeid was, moest de credietverlening beperkt worden.

Geen wonder, dat vele van de ontstemde heren met blijdschap zagen, dat van LANSBERGE op 2 Aug. 1867 naar Nederland vertrok. Men hoopte dat ,de onheilen" die hij over dit land gebracht had met hem meegingen. Maar de vrijverklaarden zagen dit vertrek met betraande ogen aan. Die van de stad boden hem als geschenk een zilveren theeblad.

Ondanks alle moeilijkheden en critiek bleef er toch ruimte over voor genot en afleiding. Een voorbeeld halen we uit het Koloniaal Nieuwsblad van I865, waarin advertenties voorkomen van het Circus Luande, dat niet minder dan vijftien voorstellingen gegeven heeft, tegen toegangsprijzen van 3 gld. voor een logeplaats, 2 gld. voor balcon en 1,50 voor parterre. Moeten wij zulks zien als een vluchten uit de werkelijkheid om de zorgen te vergeten in een andere blijde, onwerkelijke wereld?

We zien in de jaren na de Emancipatie bij de plantage-eigenaren een sombere stemming als gevolg van financiële moeilijkheden zonder hoop op uitkomst, van gebrek aan werkkrachten en van de afdaling van hun hoge positie.

Bij de contractanten onder staatstoezicht was er weinig zin tot geregelde arbeid bij de duidelijke bedoeling het op de plantage vol te houden tot het einde van het Staatstoezicht, om dan voor goed de echte vrijheid tegemoet te gaan op een grondje, of op een erf te Paramaribo. 
We zien een Gouvernement, dat pogingen doet om door immigratie de plantages te redden en dat door onderwijs de bevolking wil opvoeden tot echte burgers. Maar worsteling met nietsluitende begrotingen maakte dit Gouvernement ondergeschikt aan Moederlandse inzichten.

Nergens was de stemming opgewekt. Eerst het jaar 1873 zou opluchting brengen: voor het Gouvernement door de hoop op rijke goudvondsten na de ontdekking van J. RosenberG (K.V. I868); voor de planters door de Brits-Indische immigratie, voor de vrijverklaarden door het einde van het Staatstoezicht.

\section{BRONNEN}

waarnaar wordt verwezen

De Kolonist 13, I6 en 23 Juni 1867.

Gouvernements Blad $1856,1857,1863$.

Koloniaal Nieuwsblad 1865.

Koloniaal Verslag $1861,1862,1863,1865,1868$.

LEGÊNE: Suriname land mijner dromen, 1948; 4e druk 1952.

Rapport van de Staatscommissie I, 1855.

StaAl: in Gedenkboek Zending Ev. Br. Gem. I735-1935, 1937.

Tномsоn: Overzicht der geschiedenis van Suriname, 1902; 2e druk 1903. WeIss: Ons Suriname, 1911.

ZEEGELAAR: Suriname en de opheffing van de slavernij, 1871.

\section{S U M M A R Y}

THE GENERAL FEELING OF THE POPULATION BEFORE, DURING AND AFTER THE EMANCIPATION OF THE SLAves in Suriname

When in 1834 slavery was abolished in British Guiana, it caused great discontent among our slaves. Not a few fled to the sister-colony, thus obtaining freedom. The same discontent prevailed after the emancipation in Cayenne in 1848. About that time people in the Netherlands got a better insight into slavery, which led to the proclamation of more lenient slave-regulations in 1851 and 1856 .

The attorney-general GEFKEN rigorously applied these regulations to the slave-owners; trespassers were fined and imprisoned. Seeing this the slaves became rebellious, but then they, too, were punished as prescribed, this time not so much by whippings as by detention and hard labour. On the 3rd of October 1862 the law abolishing slavery, coming into force on the first of July 1863, was published; it brought 
no apparent change in the general sentiment of the slaves. But after the proclamation of a general amnesty for all run-away slaves, many of them returned.

At 6 o'clock on the first of July 1863 twenty one gunshots were fired announcing to 33,000 people that freedom was theirs at last. The people's joy was expressed in an appropriate way; thanksgiving services were held in all churches and a deputation went to thank Governor vAN LANSBERGE, who was visibly moved when a wreath was hung round him. Celebration went on during the following days; processions were held, there was singing and dancing, but nowhere incidents of wantonness occurred. The orderly course of this great event is generally ascribed to the preaching of the missionaries of the Moravian Brethren and to the Roman Catholic Mission.

Great displeasure among the emancipated slaves was caused by the stipulation that they would be obliged to work for wages under Statesupervision on a plantation of their own choosing for ten years Some of them, who behaved well, were exempted before the ten years had elapsed. The plantation-owners were dissatisfied with their changed condition, the low efficiency of the indentured labour and lack of sufficient funds; they, therefore, bitterly commented upon the emancipation.

The traders were discontented owing to lack of bills for foreign payments. A solution was brought about by the Surinam Bank of 1865.

The government made serious attempts to solve the labour problem by importing immigrants from India and supplying schools for the emancipated in order to educate them to industrious and dutiful citizens. 